\title{
Construction of the Online Test System for Common Basic Course in Colleges
}

\author{
Xiyun Wang ${ }^{1}$ Lei Wang ${ }^{1}$ Dongguo Li $^{2 *}$ \\ ${ }^{1}$ Beijing Institute of Petrochemical Technology, Beijing, 102600, China \\ $2^{2 *}$ Corresponding author, Capital Medical University, Beijing 100069, China
}

\begin{abstract}
The teaching of common basic course in colleges has several drawbacks, such as teachers' subject and examination-driven approach. If teaching process was shifted from curriculum-centered to studentcentered, there was a great improvement in teaching even in education. This paper suggests that it should construct an online test system for common basic course. It is possible to solve some of the problems in teaching of common basic course by applying this online test system. In this online evaluation system, the questions and knowledge points are integrated as a main link, problems and achievements (scores) are set to be a double driving force, the use of this system will enable students to go back to study.
\end{abstract}

Keywords: examination, teaching reform, online tests

\section{Introduction}

A Final examination and teachers' guide are main drivers of students' learning in traditional or current teaching mode in colleges. Classroom teaching is confined to a limited period of time. All kinds of homework usually allow students to be feeling fatigued, tired and even fear. Therefore the effectiveness and qualities of teaching are not better. On the other hand, the quality of education is vital to colleges as well as the requirement posed by the students and the society as a whole. Thus to analyze the reasons of these problems and to provide strategies for solving these problems are very necessary and important. To solve these problems existed in the teaching of the common basic courses in colleges, many teachers and researchers have made a number of reforms and practices, including, redesigning or merging the teaching contents [3,5], improving or abolishing traditional teaching methods [2,5], and changing the examination methods $[1,4,6]$.

However, there are many problems unsolved, such as students' confusions in learning, obsolete teaching methods and inflexible examination methods. Unlike previous works, based on analysis these problems, this paper suggests that it should construct an online test system and apply it in teaching for solve these problems.

\section{The analysis of the problems in teaching of common basic courses}

\subsection{College Students' Confusions}

Understanding the contents of the common basic courses is vital to the creative applications of knowledge in numerous areas. It is widely recognized that a students' ability to use the knowledge learned in college is a key element in determining subsequent success. However, these courses enable students have no interest in learning due to none direct correlations with their professional courses, 
some necessary exercises have been abandoned. The direct result is that the poor harvest of learning. Finally, the majority of students only stay in the study for the examination grade.

\subsection{Teaching Methods}

Teachers should find the appropriate methods in teaching to focus on the following three problems: the contradiction between the limited teaching hours and relatively more teaching contents, the difference of students' ability to understand knowledge points, and how to spark students' learning interest. Understanding, judgment and memory in common basic course are vital for students' learning.

With the development of computer and web technology, the text display functions, such as PPT, and its powerful computing function based on some software can be used in common basic course teaching. However, the applications of these techniques in teaching may arouse other problems relevant to understanding, judgment and memory due to less period of time to understand thoroughly. Therefore, students may be confused why we got this result, why not other inference we obtained, and how to learn effectively.

\subsection{Examination Methods}

The majority of common basic courses in many colleges have the stereotypes in previous examinations $[1,4,6]$, which focus on facts that only test the students' memory abilities. There were the following inherent problems of current examination system. Firstly, most examinations are standardized, closed-book written test with a focus on theories. Secondly, the uniformity, inflexibility in examinations make studying tedious and stressful, prohibiting students from taking the initiative and innovate during learning. Little change in examinations contents limit students' innovation. It is common that lecturers inform students the emphasis and focus of tests ahead of it. It is not helpful in culturing their independent thinking and divergent thinking to merely test students' capability to memorize what was learned. Finally, question types are mostly restricted to blank-filling, multiple-choice, true-or-false, while subjective questions like integrative question and analytical question are rare, not to mention practical problems that require students to find answers outside college. Such practice thwarts students from improving their analytical skill, independent thinking and integral capability as well as ability to put what they have learned into practice.

\section{The analysis of Strategies}

Obviously if we shifted the teaching process from curriculum-centered to studentcentered, there has a great improvement in common basic courses' teaching even in education. To achieve this challenge, the important prior work is to make a specific and accurate evaluation on students' learning status. In fact, each teacher has these experiences that students will pay attention to study due to a series quizzes in the course. Students may be attracted by the questions in the quiz or be spurred on by the score obtained in quiz. However there are many students in the lectures of common course. So a series of quizzes is too difficult to implement for teachers. In order to save the teachers' time and efforts, it is needed to build a feedback system for this evaluation, which can develop a strategy based on diagnostic tests and tracking statistics. The system can be capable of the task of information generation and transmission along with real-time processing of data. Based on the teaching philosophy of science and characteristics of the common basic course courses and curriculum requirements, we shall use intelligent methods and by means of information 
technology to build a network system, which can achieve the function of diagnostic tests, self-learning and integrity analysis.

By using this system, students can not only learn more about their own mastery of the knowledge points, but also can get a learning guidance. Teachers can not only take advantage of this system to get the status of the students' individual learning, including the existing problems, can also get the students' overall grasp of the key points and the difficult points of the knowledge they have learned.

\section{Construction of the system}

\subsection{Create the Database}

The core of the system consists of three databases: the problems, the answers and knowledge points, where the database of problems is in a dominant position. According to the syllabus of common basic course, experienced teachers were asked to choose, modify and create these questions, which are not only consistent with the syllabus requirements, but also are in line with the characteristics of students' thinking. The problems, its answer and the associated knowledge were linked by the system according to the guide of the experienced teachers. This web structure is conducive to students to learn more about the question after test.

\subsection{Design the System}

Unlike other online teaching systems, the core of our system is the database, which consists of problems, the answers and the knowledge points. The problems were chosen for further understanding of the concepts, principles and methods studied in the course. Each problem was linked to its answer and to several knowledge points. This web of problem-answerknowledge allows students to do exercises and learn more on line.

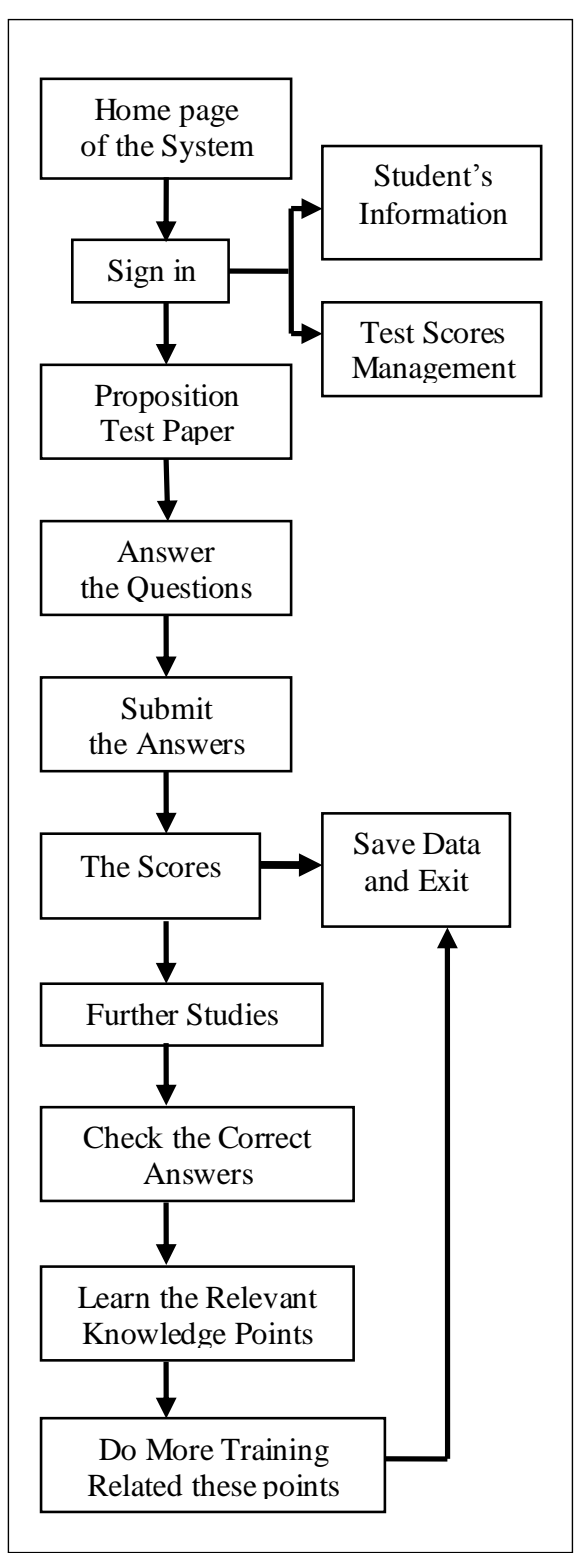

Fig. 1: The flow diagram of the online test system.

The system will achieve the following functions. First of all, the system will generate a test paper, which consists of 20 problems according to some options input by the student, including, range and the order of chapters, difficulties and em- 
phases of knowledge points, and the of difficult coefficient. Secondly, the test paper is answered online and the system checks the answer. Thirdly, the system shows the related knowledge points and gives some comments to the answer. And the further questions involved those knowledge points will be available on line. The students can answer this new test if they are willing to do. Finally, the system gives a final comment and a score. This information will save to the database, which will be a part of the course grade, and will allow the teacher to know the students' learning conditions.

\subsection{Run the System}

This system is developed in C\# development environment and the back-end database was achieved by using SQL SERVER 2000 database technology. The system is divided into three modules: the administrator module, teacher module and student module. A brief description of the student module is shown in Figure 1.

Students can enter the system at any time any where they like. After being checked the identity, each student should first determine the number of options (test content, difficulty, etc.), and then click on the button. The system then constitutes a test paper accordingly, which is displayed on the screen. By click on the start button, the student starts answer the question on the web, where the commonly used word processing software can be applied as an input tool. When the student has done all the answers, after click the submit button, the system will give the corresponding score. Thereafter the system enters a new interface for further study if the student is willing to do.

\section{Summary}

It is both necessary and feasible to reform our traditional teaching methods in order to improve effects of teaching. Although a number of methods can be applied to achieve the goals of improving effects of common basic course teaching and the quality of education, the online test system may have many advantages, such as, convenience and real-time in use, objective and full coverage of syllabus in test contents, and more information on student learning outcomes. Therefore, each common basic course should have and use its own online test system in college.

\section{References}

[1] W.Gan, K. Cai, X. Lu and X. Chen, "Discussion on ways and reforms of examination," Higher Education in Science, 8: 34-37,2000.

[2] P. Jin, T.Wei, "The reform of teaching methods on computer network," Fujian Computer 14(6):47-48,2011.

[3] X. Li, "Study on the reform of university teaching content issues," Journal of Jiangxi Institute of Education 32(4):84-87, 2011.

[4] J. Liu, "Thoughts on college examination reform teaching methods and examination methods to adapt the needs of quality education," China Higher Education Research 15(5):2829,2000.

[5] L. Li, "Reform and practice of series courses of mathematics in engineering colleges," Higher education in chemical Engineering, 3,21-24,2003

[6] J. Zhang, L. Li, H. Liu,et.al. "The advatages and disadvantages of medical higher mathematics semi-openbook examination," Journal of Shanxi Medical University, Preclincal medical education edition, 11(2):188$189,2009$. 